\title{
Trisha Brown e as artes visuais: movimentos artísticos em contato
}

\section{Trisha Brown and the visual arts: artistic movements in contact}

Giovana Beatriz Manrique Ursini ${ }^{1}$ 


\section{Resumo}

Esse artigo tem por objetivo mostrar como Trisha Brown (1936-2017) explorou instrumentos das artes visuais em suas obras de dança contemporânea. Primeiro, os recursos das artes visuais serviram como elementos cênicos em suas peças, como em Planes (1968). Depois, Brown começou a desenvolver desenhos para auxiliar na memorização coreográfica e na pesquisa de movimento. A coreógrafa desenvolveu também a série It's a Drawn onde utiliza o seu corpo como ferramenta para a pintura. Esses encontros com as artes visuais enriqueceram sua dança, ajudando no estudo corporal e na construção coreográfica. Além dos trabalhos idealizados por Brown, outras produções, como as de Merce Cunningham e Simone Forti, também são citadas ao longo do estudo para se pensar no contato das artes visuais na dança contemporânea.

Palavras-chave: Trisha Brown; artes visuais; dança contemporânea

\section{Abstract}

This article aims to show how Trisha Brown (1936-2017) explored instruments of the visual arts in her works of contemporary dance. First, the resources of visual arts were used as scenic elements in her plays, like Planes (1968). Later, Brown began to develop drawings to help in choreographic memorization and movement research. The choreographer also developed the It's a Drawn series where she uses her body as a tool for painting. These encounters with the visual arts ended up improving her dance, helping in body studies and choreographic construction. In addition to the works conceived by Brown, other productions, such as those of Merce Cunningham and Simone Forti, are also cited throughout the study to consider the contact of the visual arts in contemporary dance.

Keywords: Trisha Brown; visual arts; contemporary dance 
A pós-modernidade trouxe ideais inovadores para o campo artístico, sendo a comunicação entre diferentes linguagens artísticas um desses ideais. Tais mudanças só foram possíveis após a ousadia de artistas que criaram novas abordagens para as artes e desenvolveram diferentes maneiras para pensar uma criação artística. Nesse sentido, é importante ressaltar que esses novos direcionamentos ajudaram a desconstruir as convenções modernas e clássicas das artes. Para Andreas Huyssen:

[...] tanto o pós-modernismo dos anos 60 quanto o dos anos 70 rejeitaram ou criticaram uma certa versão do modernismo. Contra o codificado alto modernismo das décadas precedentes, o pós-modernismo dos anos 60 tentou revitalizar a herança da vanguarda europeia e dar-lhe uma forma norte-americana ao longo do que pode ser resumidamente chamado eixo Duchamp-Cage-Warhol. (Huyssen Apud Buarque de Holanda,1991, p.31)

Unir as linguagens artísticas foi umas das ideias utilizadas por esses artistas para recriarem os conceitos modernistas sobre arte. Ao unir duas manifestações distintas, os artistas encontravam mais liberdade para elaboração de suas produções e construção de novos sentidos. Tanto que os artistas pós-modernos começaram a se afastar da ideia de construir um significado único e indiscutível em uma obra de arte. Segundo Baudrillard:

A arte contemporânea explora essa incerteza, essa impossibilidade de um juízo de valor estético consistente e especula sobre a culpabilidade dos que nada compreendem disso tudo, ou que não compreenderam que nada havia a compreender. (Baudrillard, 2002, p.138)

A estética contemporânea acaba se desvinculando dos princípios de "se fazer entender", ideias que eram comuns nas artes clássicas e modernas. Os artistas da pós-modernidade começaram a se preocupar, então, em fazer arte pela arte, sem preocupar com um significado puro, trazendo diferentes ideias e abrindo espaço para estranhamento e abstrações.

Um dos conceitos arquitetados no período contemporâneo foi o contato da dança com instrumentos de outras linguagens artísticas. Para exemplificar, pode-se citar a ideia de dança-teatro onde, "a dança é revelada e o teatro é empurrado para uma nova direção fazendo com que essas duas formas se incorporem em um conjunto harmonioso [...]"2 (Climenhaga, 2009, p. 2). Pina Bausch trabalhou com esse conceito na sua dança contemporânea. Nessa manifestação artística, a dança e o teatro se unem para o desenvolvimento de uma técnica na dança. Nesse conceito, o bailarino usa apenas o seu corpo para representar personagens e narrativas.

Os coreógrafos de dança pós-moderna acabaram, então, tendo mais liberdade para edificar ousadas criações e utilizavam novas ferramentas para a construção de suas coreografias, como por exemplo, a criação coreográfica através de gestos cotidianos como em Trio A (1965) de Yvonne Rainer. Empregar os recursos das artes visuais também foi uma das técnicas utilizadas por esses artistas.

Para comprovar a presença de instrumentos das artes visuais na dança contemporânea, a obra de Trisha Brown é utilizada como objeto de estudo, visto que essa

${ }^{2}$ Dance is uncover and theater is pushed in a new direction as the two forms are merged into a seamless whole. [...]". (Tradução nossa) 
artista aplicou certos elementos das artes visuais nas suas coreografias e conseguiu demarcar o seu próprio estilo. Dentre esses elementos estão: o desenho, a action painting ${ }^{3}$ e o vídeo. Além de ajudar na composição de seus trabalhos, a utilização desses instrumentos ajudou a modificar a sua própria maneira de enxergar a dança. Por exemplo, a série It's A Drawn, na qual a artista cria desenhos ao vivo com movimentos gestuais, é uma obra que representa a sua ideia de unir o ato de desenhar com movimentações de dança.

A presença das artes visuais em outras produções de dança contemporânea também será discutida, como o uso de características da escultura minimalista no desenvolvimento coreográfico de Simone Forti e o uso do vídeo como ferramenta de anotação empregado por Merce Cunningham.

\section{Dança contemporânea e artes visuais}

A dança contemporânea conseguiu alterar as convenções presentes nas formas clássicas e modernas dessa arte. Os artistas pós-modernos criaram espetáculos que exploravam novos movimentos gestuais para o corpo e, nesse contexto, espaços alternativos começaram a ser testados, a relação entre música e coreografia foi modificada e a dança estabeleceu interações com outras formas artísticas.

Segundo Banes (1979), os coreógrafos contemporâneos usavam outras fontes para a criação de suas revolucionárias experimentações. Estruturas e atitudes performáticas das artes visuais, da música, da poesia e do teatro foram agregadas em obras de dança contemporânea, resultando no desaparecimento das bordas entre as linguagens artísticas e novas estratégias de produção artística nessa arte.

Os coreógrafos pós-modernos buscavam, então, formas inéditas para as suas coreografias, com o objetivo de remodelar a visão comum sobre um espetáculo de dança. Em outras palavras, esses artistas negavam as ideias mais populares sobre como deveria ser um espetáculo de dança, como por exemplo, uma coreografia realizada em um palco tradicional com o uso de figurinos próprios para se locomover em uma sequência gestual. Ferramentas que acabaram padronizando uma visão única para se enxergar a dança e que eram criticadas pelos coreógrafos de dança contemporânea.

Nesse sentido, novas produções eram idealizadas para a conquista de diferentes resultados, trazendo um caráter experimental para essa arte com características essenciais da arte contemporânea, tais como: o estranhamento, a incerteza, a indeterminação, a histeria, o colapso e o desconforto existencial (Machado, 2010). Essas particularidades foram ampliadas na dança após o uso de estéticas e estruturas incomuns a um espetáculo dançante. As experimentações pós-modernas nessa arte cênica conseguiram retirar das fontes mais alternativas, objetos criativos que acabaram trazendo estranhamentos, novos sentidos e experiências que enriqueceram o cenário dessa nova dança.

Para exemplificar como certas linguagens das artes visuais foram utilizadas em espetáculos de dança pós-moderna, pode-se mencionar o vídeo, empregado por

\footnotetext{
${ }^{3}$ Action Painting é uma técnica conceituada por Harold Rosenberg em 1952. Consiste em apresentações que mostram pinturas abstratas sendo produzidas pelas mais diversas ações, por exemplo, tintas sendo gotejadas em uma tela branca. O principal expoente dessa técnica foi Jackson Pollock (1912-1956).
} 
artistas para facilitar a recuperação de uma sequência antiga de movimentos, como no caso do coreógrafo Merce Cunningham (2014, p. 187):

Jacqueline Lesschaeve: De que maneira você usa o vídeo ao ensaiar uma dança antiga? Você assiste à fita inteira antes de ensaiar?

Merce Cunningham: Eu faço com que os dançarinos assistam à fita, daí eles vêm e experimentam. Assistem de novo, eu assisto, e gradualmente recuperamos a coisa. As fitas ajudam muito. São úteis, sobretudo, para os dançarinos que conhecem os papéis e não os fazem há muito tempo: refrescam a memória deles. Mas podem ajudar até os que nunca fizeram dança.

Como o estudo de uma coreografia é feito a partir da constante repetição dos gestuais propostos, os vídeos mantêm as imagens gravadas para serem retransmitidas em outras situações. Essas repetições conseguem auxiliar os bailarinos que desconhecem uma sequência e também ajuda na memorização de elementos coreográficos. Cunningham, além de recuperar gestuais, empregava as imagens gravadas na tela para propor novas direções para suas obras. No entanto, o vídeo não era capaz de recuperar o movimento por completo, visto que a câmera da época era capaz de captar apenas um ângulo do corpo daquele que dançava.

Na década de 1980, os recursos para a idealização de um vídeo eram escassos, assim, Cunningham aproveitava essa ferramenta tecnológica para auxiliar na elaboração de suas criações, transformando-a em um instrumento para a construção do seu estilo. Isso aproximou o coreógrafo da ideia defendida por Machado (2010, p. 16) quando menciona que "[...] o artista [...] busca se apropriar das tecnologias mecânicas, audiovisuais, eletrônicas e digitais numa perspectiva inovadora, fazendo-as trabalhar em benefício de suas ideias estéticas". Assim, o artista usa a tecnologia do vídeo para aperfeiçoar as suas danças e esse elemento novo é explorado para ajudar na transformação de suas ideias em gestuais coreográficos.

Além do vídeo, Cunningham utilizava a tecnologia dos computadores para a construção de suas coreografias. Mais precisamente, o artista usava um software denominado Lifeforms. De acordo com Schiphorst (1993), Lifeforms é um software de composição para a criação de danças. Foi desenvolvido em 1986 na Simon Fraser University. Pensado e desenvolvido como uma ferramenta criativa para coreógrafos, essa ferramenta promovia uma interativa e gráfica interface que possibilitava aos coreógrafos esboçar ideias de movimentos.

Essa tecnologia foi manuseada por Cunningham para o desenvolvimento de sequências gestuais, como por exemplo, a peça Trackers (1991) que teve uma parte coreografada através dessa ferramenta. Utilizar um recurso gráfico ao invés do corpo para criar ideias dançantes, deixou o coreógrafo mais livre para estudar imagens e movimentos abstratos que poderiam ser mais difíceis de ser explorados por causa da limitação da matéria orgânica.

As artes visuais também encontraram a dança devido ao uso de características da escultura minimalista em certas coreografias. Como exemplo, podemos apontar a estética dos trabalhos produzidos pela artista italiana Simone Forti: 
de [Simone] Forti com Plywood Show de [Robert] Morris, deixa claro esses aspectos da prática de Forti e traz a atenção merecida a sua contribuição para uma estética minimalista [...]. Enquanto uma apresentação de dança pode inicialmente não estar relacionada com uma exposição da obra de Morris, Forti situou cada uma de suas danças, nas quais foram nomeadas Dance Constructions, de forma semelhante às esculturas de uma galeria. (Spivey, 2009, p. 13) ${ }^{4}$

Forti esperava que seu público pudesse experimentar as suas criações de dança como se fossem esculturas minimalistas, pois algumas das características de seus trabalhos relacionavam-se com traços dessas obras. Entre elas, estão as coreografias idealizadas com poucos recursos, tanto cênicos quanto corporais, ideia que se assemelha ao ideal de Morris (apud Battcock, 1968) de que a simplicidade da forma não equivale necessariamente à falta de experiência, enfatizando que mesmo com poucos elementos estéticos, a experiência da obra de arte pode ser ampla e reflexiva.

Outra característica utilizada por Forti em seus trabalhos é a tridimensionalidade que deixava o público visualizar a dança por diversos ângulos. Segundo Donald Judd, as qualidades da tridimensionalidade são:

No trabalho tridimensional, a coisa toda é feita com propósitos complexos, e esses não estão dispersos, mas são afirmados por uma forma única. Não é necessário para um trabalho ter um monte de coisas para olhar, para analisar uma por uma, para contemplar. A coisa como um todo, sua qualidade como um tudo, é o que é interessante. (Judd apud Ferreira; Cotrim, 2006, p. 103)

Ao pensarmos nas obras de dança de Forti, temos a presença da tridimensionalidade quando a coreógrafa elabora uma coreografia com apenas um movimento e permite que o público se desloque ao redor das suas criações para que possa perceber a obra por diversos ângulos, dando a noção de esculturas em movimento. A ideia de acrescentar elementos da escultura minimalista na dança se deve ao interesse individual de Forti pelas artes visuais, visto que antes de ser bailarina, a artista era pintora. Uma das dance construtions (construções na dança) desenvolvidas pela coreógrafa foi nomeada Huddle, uma obra que misturava instrumentos minimalistas com os movimentos do corpo dos bailarinos, desenvolvendo uma "escultura corporal".

De acordo com Spivey (2009), Huddle é um trabalho realizado sem nenhum suporte adicional. Nesse espetáculo seis ou sete bailarinos formam um círculo curvado para frente com os participantes unindo os seus braços ao redor de suas cinturas e ombros. A dança tem início quando uma pessoa se solta do círculo e começa a escalar essa estrutura humana usando apoios de pés e mãos formados pelos corpos dos outros bailarinos. Não existe nenhuma regra para a escala dessa escultura corporal, e o público se move ao redor do grupo para perceber as alterações propostas pelos bailarinos.

Os dançarinos acabam construindo uma escultura em movimento, o que se assemelha a um trabalho minimalista pela maneira como os seus elementos são construídos. As únicas ferramentas empregadas no desenvolvimento dessa criação são os

\footnotetext{
${ }^{4}$ A comparison of Forti's "Five Dance Constructions ad Some Other Things" (1961; Fig. 1) to Morris's "Plywood Show" sheds light on these aspects of Forti's practice and brings deserved attention to her contribution to a Minimalist aesthetic. Forti's concert included five new dances, Slant Board, Huddle, Platforms, Hangers. [...] While a dance performance may initially seem unrelated to the exhibition of Morris's artwork, Forti situated each of her dances, which she called "dance constructions," in a manner akin to sculptures in a gallery. (Tradução nossa)
} 
corpos dos bailarinos que apenas precisam realizar um movimento: escalar o círculo formado por outros participantes do experimento. Essa peça também emprega a ideia de tridimensionalidade, que é aparente no movimento do público para enxergar o espetáculo de diferentes ângulos.

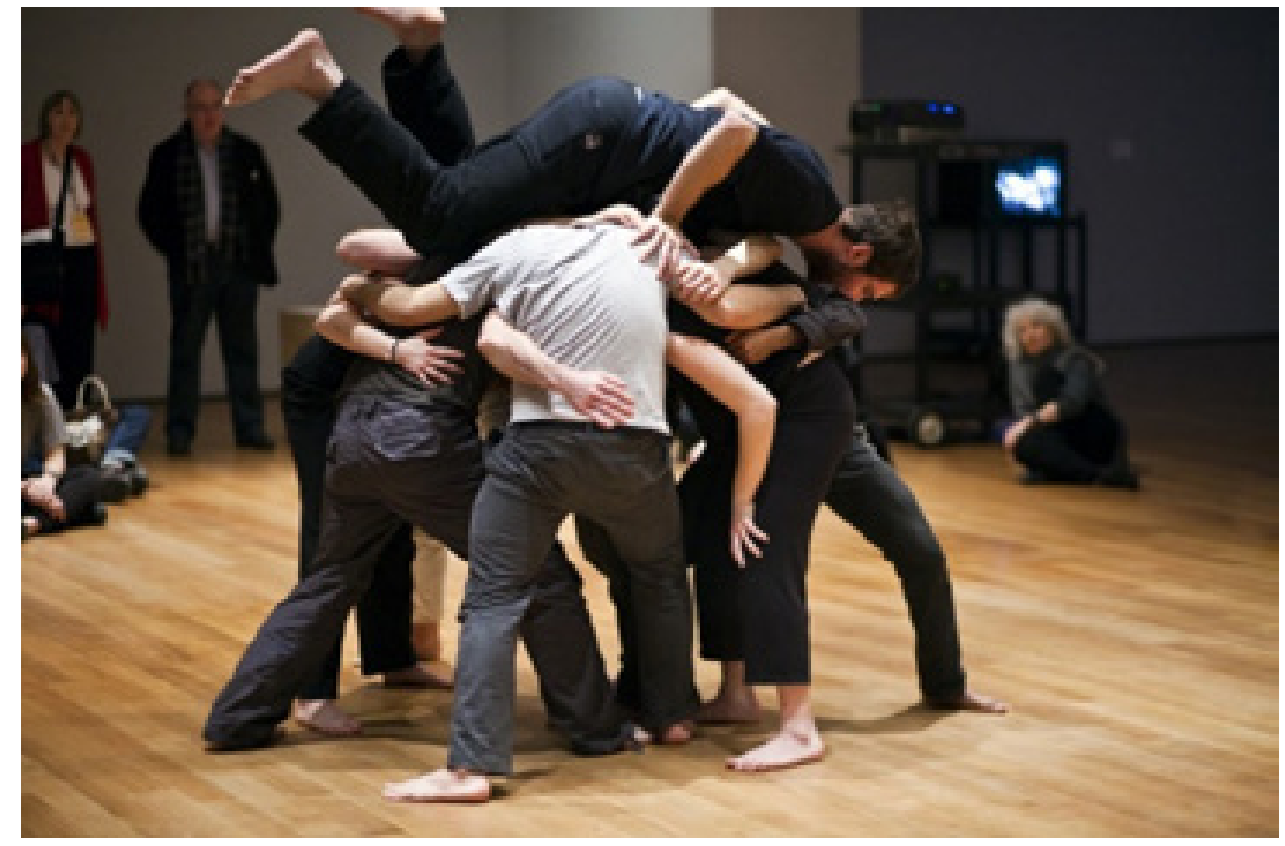

Huddle. Coreografia idealizada por Simone Forti. Imaginada como uma escultura corporal ${ }^{5}$

\section{Trisha Brown}

Trisha Brown é uma coreógrafa e bailarina nascida em 25 de novembro de 1936, nos Estados Unidos. A artista iniciou seus estudos na dança aos 13 anos, quando começou a ter aulas de balé clássico e sapateado. Anos mais tarde, Brown cursou a sua graduação na Milles College (Sommers, 1972). Nesse período, a bailarina desperta revolta contra as técnicas da dança moderna que aprendia na universidade. Essa negação pelos padrões modernos da dança a impulsionou a desenvolver sua própria "marca" nessa linguagem artística. Brown ficou mundialmente conhecida pelas suas ideias inovadoras e por sua forma de dançar, visto que seu estilo une instrumentos incomuns às convenções estabelecidas pelas danças clássicas e modernas.

Em 1962, a bailarina se une a Simone Forti, Yvonne Rainer, à musicista Meredith Monk e a outros talentos para fundar o Judson Dance Theatre. Esse círculo artístico ficou conhecido pela quantidade de obras produzidas em um curto espaço de tempo (300 produções cênicas foram elaboradas em quatro anos) e pela variedade artística dos integrantes desse grupo:

Os artistas da Judson compartilhavam um comprometimento anárquico de derrubar as regras comuns a um espetáculo de dança. Eles não confiavam nas altas técnicas físicas por si só e ao invés disso utilizavam tasks, acaso e formas de movimentos cotidianas (às vezes interpretadas por não dançarinos) em um esforço para trazer a dança para a vida cotidiana [...]. Espaço vertical além do horizontal também foi explorado, coreografias pré-ensaiadas foram combinadas com im-

${ }^{5}$ Fonte: http://www.danspaceproject.org/calendar/simone-forti-movement-and-writing-workshops-body-mind-world/. Acesso em: 18 nov. 2017. 
provisação, e elementos de filmes e da arte visual também foram incorporados. (Bither apud Eleey, 2008, p. 9-10) ${ }^{6}$

As ideias partilhadas pelos participantes do Judson Dance Theatre eram revolucionárias para os conceitos sobre dança que existiam naquela época, no início dos anos 1960, quando as técnicas da dança moderna e da dança clássica eram populares nas escolas de dança e nas universidades. Fazendo com que as ideias sobre dança estivessem relacionadas com essas metodologias.

Dessa forma, certos instrumentos que eram comuns nessas técnicas começaram a ser questionados pelos artistas do Judson Dance Theatre. Como por exemplo, o uso de narrativas na dança, a alta expressividade dos movimentos e a preocupação excessiva com a virtuosidade técnica. Essas ferramentas foram negadas por esses artistas que as consideravam limitantes para suas criações na dança. Portanto, a ousadia desses artistas ajudou a desenvolver novas visões para essa arte.

Depois de ser uma participante do Judson Dance Theatre Brown continuou com a sua carreira solo e em 1970 fundou a Trisha Brown Dance Company. A companhia segue com as suas atividades até os dias atuais, no entanto, em 2013, Brown se aposentou dos palcos, aos 77 anos de idade. Trisha Brown faleceu em 18 de março de 2017 nos Estados Unidos.

Para comprovar a importância dos mais de 40 anos de pesquisa na dança da coreógrafa, é possível expor alguns elementos da sua obra. Por exemplo, o seu interesse em desafiar a gravidade, colocando os seus bailarinos em situações extremas para vencerem a força gravitacional:

O primeiro grupo de projetos não relacionados com o Judson, realizados por Brown, mais tarde foi conhecido como "ciclo de equipamentos", no qual Trisha usava vários adereços e simples mecanismos como polias, escudos e cordas para celebrar e confrontar gravidade. Esse ciclo colocava corpos em situações extremas, jogando com duração, envolvendo leis da engenharia e da física, e representando movimentos puros[...]. (Bither apud Eleey, 2008, p. 10) ${ }^{7}$

A artista pós-moderna chegou a utilizar os mais diversos equipamentos para desafiar a força da gravidade. Em alguns de seus trabalhos colocava seus bailarinos se movimento nas paredes de um museu como em Walking on the Wall (1971), dançando em paredes de escalada em Planes (1968) ou descendo um prédio verticalmente na produção Man Walking Down The side of a Building (1970).

Boa parte das coreografias desenvolvidas por Brown eram realizadas em locais alternativos ao edifício teatral. Estacionamentos abandonados, ruas, galerias de arte, museus e até prédios abandonados eram lugares escolhidos como locais de apresentação (Bither apud Eleey, 2008), o que mostra que a bailarina norte-americana conseguia ajustar as suas ideias coreográficas para as mais diversas arquiteturas. Es-

\footnotetext{
${ }^{6}$ Judson artists shared an anarchic commitment to upending the governing rules of concert dance. They distrusted physical virtuosity for its own sake and instead utilized tasks, chance, and everyday movement forms (sometimes performed by non-dancers) in an effort to bring dance closer to everyday life. They discarded other elements they felt only added artifice to stage [...]. Many of Judson artists abandoned music as well, preferring silence, electronic, or found sound. Vertical as well as horizontal space was explored, set choreography was combined with improvisation, and elements of film and visual art were often incorporated. (Tradução nossa)

${ }^{7}$ Brown's first grouping of non-Judson-related projects, later termed her "equipment cycle," used various props or simple mechanisms such as pulleys, harnesses, and ropes to both celebrate and confront gravity. The cycle put bodies in extreme situations, played with duration, involved engineering and the laws of physics, and represented pure movement. (Tradução nossa)
} 
sas obras em locais alternativos eram site-specific porque se relacionavam com o espaço onde estavam sendo realizadas. Exemplificando, a peça Walking on the Wall (1971), idealizada para ser apresentada nas paredes do Whitney Museum of American Art. Mostrando que Brown criava peças para serem executadas em locais diversos, enfatizando a sua ideia de explorar diferentes espaços com sua dança.

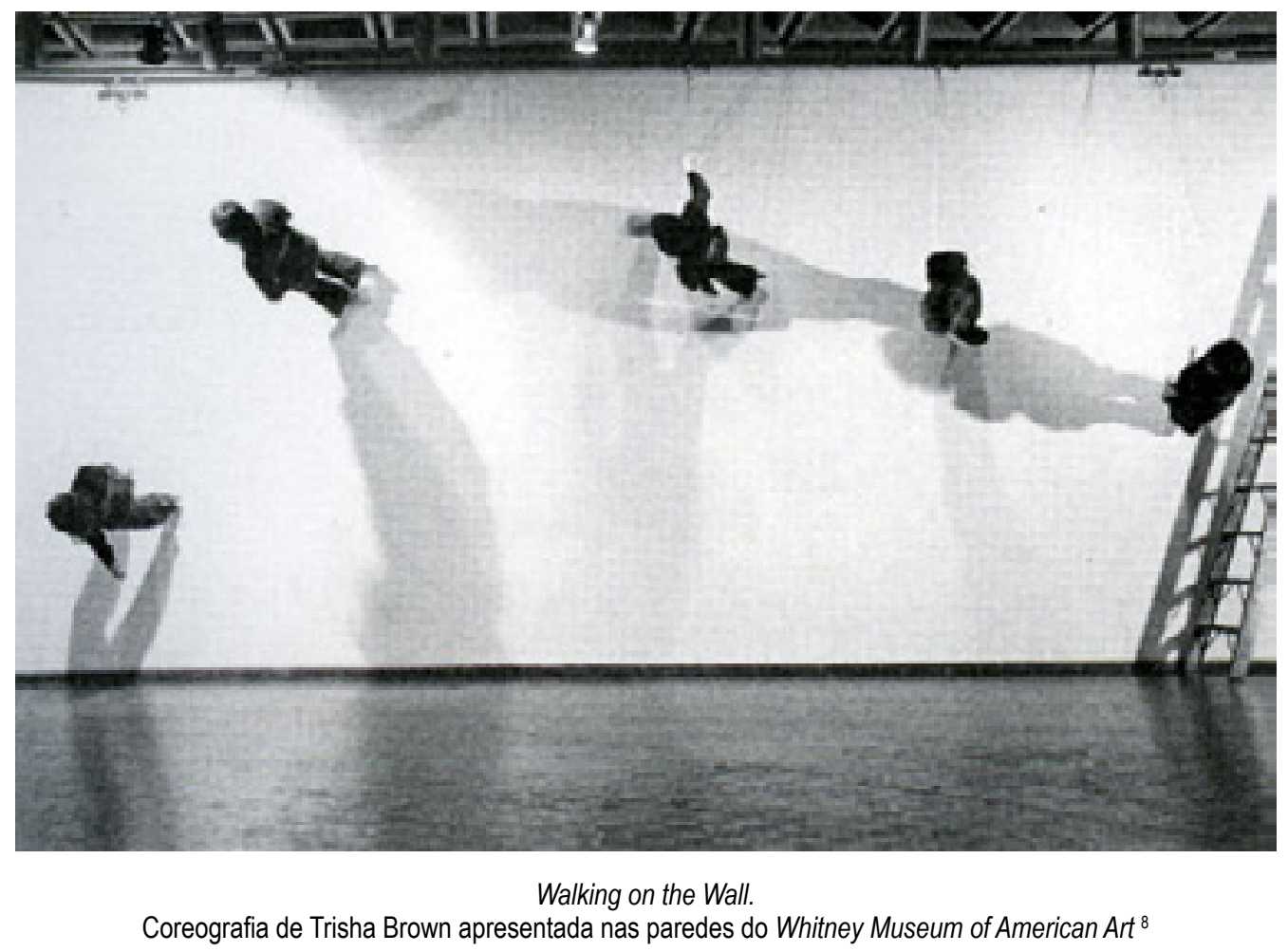

Essa coreógrafa também começou a explorar outras partes do corpo na sua dança. Segundo Banana (2012, p. 87):

A iniciação do movimento em Trisha pode começar a qualquer onde-quando. Não há preparação para iniciar os seus movimentos. São diretos, objetivos e não há um tipo de pantomima do próprio movimento, não há ênfase em certos movimentos em detrimentos de outros. Nesse sentido, não há hierarquia no conjunto de movimentos e do mesmo modo que pode começar de qualquer parte do corpo, pode acabar.

Brown passou a elaborar novas maneiras de construir movimentações, iniciando seus movimentos através dos mais diversos vetores, não apenas no centro, mas em outras partes do corpo. Como por exemplo, gestos originados por impulsos nos ombros, nas pontas do corpo, no pescoço e na cabeça. Essa técnica acabou desenvolvendo diferentes desenhos corporais e negou a ideia de "gestos belos". Através dessa nova abordagem do corpo dançante, a bailarina desenvolveu movimentos abstratos e esse contexto lhe impulsionou a criar o seu próprio vocabulário corporal.

\section{As artes visuais na obra de Brown}

Trisha Brown utilizou instrumentos de diversas manifestações artísticas na cons-

${ }^{8}$ Fonte: https://www.trishabrowncompany.org/?page=view\&nr=481. Acesso em: 17 nov. 2017. 
trução de seus trabalhos e alguns desses elementos eram originados das artes visuais. A coreógrafa chegou a cooperar com criadores dessas manifestações artísticas para agregar princípios das artes visuais em suas peças, tanto que "Brown também colaborou com artistas de vídeo, multimídias e filmes. Entre eles: Robert Whitman em Homeland (1966), Jud Yalkut em Planes (1969) e Babette Mangolte, que documentou Roff and Fire Piece (1973)" (Lee, 2011, p. 14). ${ }^{9}$

Aliando a sua paixão pelas artes visuais com as suas ideias criativas na dança, Brown soube interligar essas duas formas artísticas para criar novas atmosferas em algumas de suas obras. Um dos pontos experimentados por Brown nas suas apresentações foi o uso do vídeo. A coreógrafa era auxiliada por artistas dessa área para acrescentar novas ferramentas nos seus espetáculos. O elemento do vídeo era utilizado como uma espécie de objeto cênico que engrandecia os cenários de suas experimentações.

Em Homemade (1965), Brown desenvolve uma coreografia adotando gestuais cotidianos, como arremessar uma linha de pesca, medir uma caixa ou telefonar (Burt, 2006). Enquanto a bailarina executa a sua movimentação, um vídeo é projetado em uma tela atrás da artista por meio de um projetor preso nas suas costas. Segundo Burt (2006), o filme utilizado nessa peça foi criado por Robert Whitman e mostra a coreógrafa executando os mesmos movimentos que estão sendo desenvolvidos ao vivo. Enquanto Brown executa sua sequência gestual, as imagens projetadas movem-se juntamente com a artista, percorrendo outros pontos da arquitetura do espaço da apresentação.

O vídeo consegue ajudar na exploração coreográfica de locais que não seriam possíveis para a coreografia investigar fisicamente, como o teto. Assim, o filme de Whitman se transforma em um elemento cênico da coreografia de dança, e o público, ao assistir ao espetáculo, tende a comparar as duas apresentações da mesma sequência gestual. Ao longo da apresentação, é possível perceber as diferenças de velocidade de cada movimento. O corpo de Trisha tem as suas ações dificultadas pela presença do projetor, e o vídeo tem problemas na reprodução das imagens. $A$ gravação foca em partes do corpo se locomovendo, e a audiência analisa o corpo por completo na apresentação ao vivo.

Em outro momento da sua carreira artística, Brown começa a usar o vídeo como uma espécie de anotação. Esse instrumento é empregado para gravar uma coreografia, ajudando no processo de memorização de movimentações. Babette Mangolte, ao citar o processo de gravação de Watermotor, pontua que:

Por causa do completo desafio e velocidade da dança, eu também senti que as capacidades físicas da bailarina precisavam ser tão bem ajustadas que Trisha talvez não fosse capaz de dançar isso por muitos anos e, portanto, a gravação de um filme era urgente e não devia ser adiada. Apesar de Trisha rir do meu medo de que ela não seria capaz de realizar essa obra por muitos anos, ela concordou que eu pudesse filmá-la. (Mangolte apud Lepecki, 2012, p. 187) ${ }^{10}$

\footnotetext{
${ }^{9}$ Brown also collaborated with multimedia, film and video artists, including Robert Whtiman on Homemade (1966), Jud Yalkut on Planes (1969) and Babette Mangolte, who documented Roof and Fire Piece (1973). (Tradução nossa)

${ }^{10}$ Because of the dance's sheer bravado and speed I also felt that the physical abilities of the dancer had to be so fine-tuned that maybe Trisha would not be able to dance it for many years to come and therefore the film recording of it was urgent and should not be delayed. Although Trisha laughed at my fear that she was not going to be able to perform it for many more years she agreed that I could film it. (Tradução nossa)
} 
Essa coreografia engloba variados movimentos, dentre eles: movimentações rápidas com o braço, pulos, giros e momentos com gestuais mais lentos e até pausas. Por ser uma peça realizada com diversos movimentos, o vídeo conseguiu ser uma ferramenta importante para gravar a sequência proposta pela coreógrafa. Mesmo que Brown não seja capaz de relembrar toda a movimentação, o vídeo é capaz de manter esses gestuais gravados.

Apesar de a artista explorar elementos das artes visuais nas suas peças, esses instrumentos eram apenas coadjuvantes em seus trabalhos. Em outro período de sua obra, Brown começa a desenvolver os seus próprios trabalhos visuais, desenhos que serviam como uma espécie de roteiro para o que a artista estava idealizando em suas coreografias. Esses desenhos a auxiliavam a entender o corpo que dança e como esse material orgânico pode ser trabalhado em cena, como se fosse possível desenhar tudo o que seria dançado.

De acordo com Dai (2016), com o intuído de trabalhar abstratamente, Brown começou a desenhar em 1973. A coreógrafa utilizava desenhos como notações de seus materiais de dança, criando registros que complementavam as suas coreografias. Essa forma artística foi uma maneira que Trisha Brown encontrou para ajudar na construção de seu próprio vocabulário corporal. Onde os desenhos a ajudavam a compreender como e através de quais movimentos corporais o seu estilo coreográfico era desenvolvido.

Essas anotações gráficas eram importantes não apenas para o entendimento das suas propostas coreográficas, mas também ajudavam no desenvolvimento de outras coreografias. Segundo Eleey (2008), Brown usou o desenho como uma forma de exercício mental, para retratar uma continuidade ou acúmulo de movimento que a artista esperava em seus dançarinos.

Assim, os desenhos, além de servirem como gravação do que já havia sido desenvolvido, ajudavam a coreógrafa a pensar no que seria criado juntamente com os integrantes de sua companhia. O uso dos desenhos como mecanismos de criação agregou qualidade a seus movimentos, fazendo com que estes fossem abstratos, geométricos e repetitivos (Dai, 2016), características presentes nos desenhos e que foram traduzidos para a dança por Trisha Brown. Os desenhos ajudavam no registro e na construção coreográfica. Movimentos abstratos em dança eram criados através de desenhos também abstratos.

Tanto como anotações de dança quanto como instrumentos para criações de movimentações, os desenhos desenvolvidos por Trisha Brown relacionavam-se com a dança e com o corpo que executa uma coreografia. Para entender a relação entre dança, corpo e desenho, é possível ilustrar algumas formas estéticas presentes nos trabalhos de artes visuais da coreógrafa. Para Eleey (2008), os entrecruzados e os cubos cortados em quatro partes, desenhados pela artista, tentavam reproduzir o corpo divido em primárias unidades, em variadas combinações de movimentos. Já os quadrantes serviam para representar os membros do corpo do bailarino.

Os desenhos produzidos por Brown eram feitos por meio de formas simples, mas que conseguiam fazer uma análise minuciosa da matéria da dança. A artista era capaz de estudar e experimentar até as menores unidades corporais por meio de seus desenhos. Além dos entrecruzados e quadrantes, a coreógrafa utilizava a linha 
para representar movimentações. O uso dessa forma gráfica também foi aplicado na composição de algumas de suas coreografias e foi a forma que a ajudou a desenvolver gestuais abstratos tanto nos desenhos quanto em suas coreografias (Dai, 2016).

Para exemplificar o uso de desenhos nas coreografias de dança criadas por Trisha Brown, pode-se citar as anotações para a peça Locus. Por ser uma coreografia com gestuais complicados de serem memorizados, Brown resolveu desenhar uma partitura para as movimentações criadas, utilizando um cubo organizado em torno de pontos numéricos, cada um correspondendo a uma letra do alfabeto. Localizado no centro do cubo, existia um ponto para designar o espaço entre as letras. Depois de transformar os números e letras, Brown passava as instruções coreográficas a partir de textos antigos, nos quais cada letra e cada palavra representavam um movimento de dança (Graham, 2016).

Essas anotações foram criadas pensando no formato do cubo porque o espaço do espetáculo representava um cubo imaginado pela coreógrafa. Ou seja, todos os gestuais propostos nessa coreografia foram pensados para se encaixarem nesse cubo inexiste ao olhar do público. Os passos dessa peça precisam respeitar a arquitetura virtual do cubo que só era existente nos desenhos e na mente da artista. Os desenhos acabavam sendo traduzidos através dos corpos dos bailarinos.

${ }^{11}$ Fonte: http://walkerart.org/collections/publications/performativity/drawings-of-trisha-brown/. Acesso em: 17 nov. 2017. 


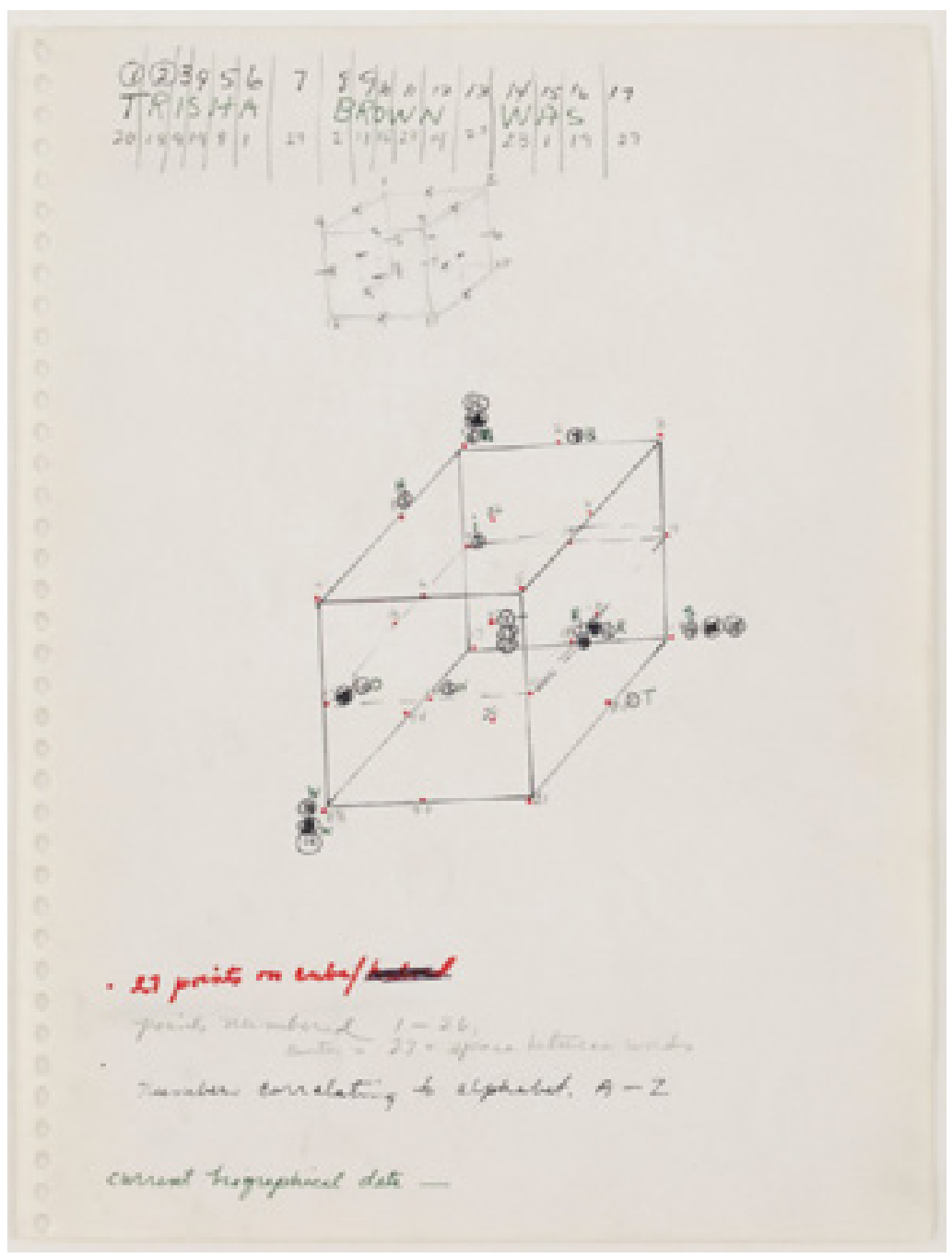

Locus. Desenhos da peça realizados por Trisha Brown para pesquisar a arquitetura virtual do cubo na coreografia de dança ${ }^{12}$

A ideia de produzir desenhos para representar suas coreografias surgiu após Trisha Brown começar a investigar a ideia de notação na dança. O seu primeiro contato com esse conceito foi em um curso ministrado por Robert Dunn. Segundo Dai $(2016, \text { p. 8) })^{13}$ :

Além de encorajar os estudantes a criarem novas formas, Dunn, ao mesmo tempo, estava introduzindo Labanotation e outros sistemas de notação de movimentos para dançarinos e coreógrafos. Para Dunn, a escrita e o desenho da dança eram cruciais para objetivar tanto a composição quanto o processo criativo. A notação obrigava o pensamento lógico enquanto oferecia um procedimento para transferir e materializar pensamentos como palavras e desenhos.

A coreógrafa começou a usar a anotação como uma investigação do corpo. Esse estudo a ajudou tanto no entendimento de suas coreografias quanto na construção de novas sequências de movimentos, sendo que os primeiros desenhos da artista tentavam compreender a lógica do corpo e da dança.

\footnotetext{
${ }^{12}$ Fonte: http://artjournal.collegeart.org/?p=7351. Acesso em: 17 nov. 2017.

${ }^{13}$ Apart from encouraging students to invent new forms, Dunn at the same time was introducing Labanotation and other movement notation systems to dancers and choreographers. For Dunn, the writing and drawing of dance were crucial to objectify both the composition and the creative process. Notation imposed logical thought while offering a procedure for transferring and materializing thoughts as words and drawing. (Tradução nossa)
} 
Além de Brown, a coreógrafa Yvonne Rainer também utilizou desenhos em uma partitura para estudar as movimentações de suas coreografias. Segundo Banes (1993), Rainer elaborou um plano espacial conectando pontos em um pedaço de papel. Também no papel estavam palavras dispersas que poderiam indicar movimentos e partes do corpo. Na mesma folha tinham números de um a dez que indicavam a velocidade do movimento. Interessantemente, as duas artistas usavam formas simples para representar os movimentos de suas coreografias. Desenhar sequências gestuais antes de executá-las provavelmente as ajudou no entendimento do movimento da dança. Tanto Brown quanto Rainer participaram do curso ministrado por Robert Dunn.

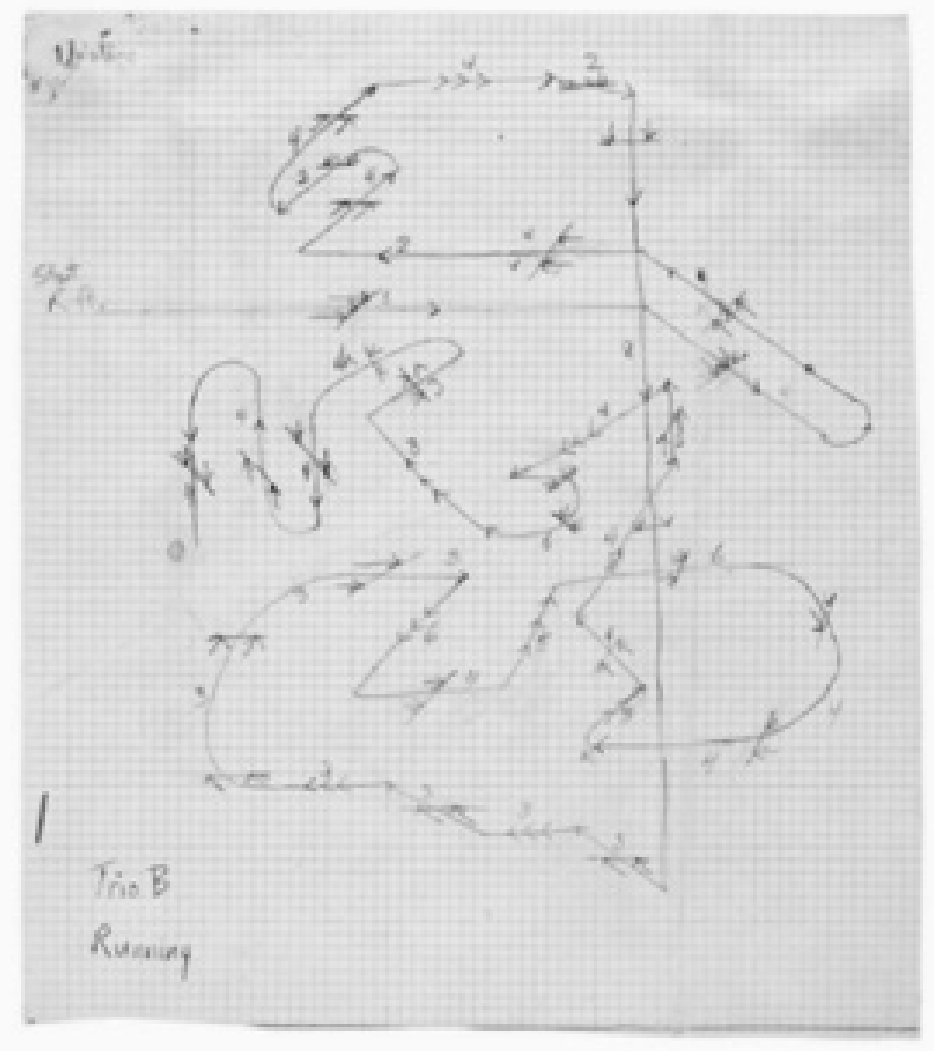

Notação para a coreografia Trio B. Desenho realizado por Yvonne Rainer ${ }^{14}$

Mais adiante, em sua obra, Trisha Brown começou a fazer live performances, nas quais desenvolvia gravuras com seu corpo em movimento. Esses espetáculos transformaram-se em uma série que foi nomeada It's a Drawn, iniciada em 1999. As principais ações que a coreógrafa realizava durante essas apresentações eram:

Se movendo de um lado para o outro nesse espaço com um giz ou grafite nos seus pés, rolando, girando, sentando novamente, empurrando, escorregando, pulando, trocando, destruindo os materiais, saltando e gaguejando em cima da superfície (ou atravessando o espaço entre as folhas de papel), polindo e empurrando a textura do solo abaixo, suando, correndo, remexendo, manchando, marcando um $\mathrm{x}$ no lugar, esperando: Brown cria um misterioso romance em duas dimensões. (Eleey, 2008, p. 25) $)^{15}$

\footnotetext{
${ }^{14}$ Fonte: http://walkerart.org/collections/publications/performativity/drawings-of-trisha-brown/. Acesso: em: 17 nov. 2017.

${ }^{15}$ Moving across it with pastels or graphite in her toes, rolling over, pivoting, sitting back, pushing, skidding, pulling, swooping, breaking her materials, skipping and stuttering them over the surface (or across the gap between sheets), thrusting, rubbing up the texture of the floor beneath, sweating, scooting, fidgeting, smearing, X-marking-the-spot, lying in wait: Brown creates a mystery novel in two dimensions. (Tradução nossa)
} 
A partir dessas ações, Brown parecia tentar desenhar os seus gestos, provavelmente na tentativa de traçar sua dança no papel. Essa produção artística envolve tanto a ação de desenhar quanto a de dançar, isto é, os movimentos corporais propriamente ditos. Consequentemente, a artista coloca o corpo em evidência em ambas as ações, enfatizando uma tendência pós-moderna de estudar o corpo que dança:

Questões sobre o corpo e os seus poderosos significados sociais foram abordados
de cabeça erguida. O corpo por si só virou objeto para a dança, ao invés de apenas
servir como um instrumento para metáforas expressivas. Uma ousada análise do
corpo, suas funções e poderes foi iniciada pelas primeiras danças pós-modernas.
[...] Os coreógrafos intencionalmente usavam dançarinos amadores na procura de
um o corpo "natural”. Ex: Brown, Fort e as improvisações violent contact de Dick
Levine (Banes, 1979, p. 3) 3 (16 $^{16}$

A pós-modernidade trouxe a ideia do corpo como principal objeto de estudo de uma coreografia, desconstruindo a ideia do corpo como mera ferramenta para transmissão de emoções e para contar uma narrativa. O uso da gravura do corpo como uma forma de explorar e analisar o próprio corpo confirma esse ideal que transforma a matéria orgânica como elemento principal em uma coreografia. Não apenas essa série, mas boa parte dos desenhos produzidos pela artista norte-americana tentam estudar a matéria orgânica em movimento. A ferramenta dos desenhos transformase, então, em um instrumento para análise e representação das movimentações coreográficas.
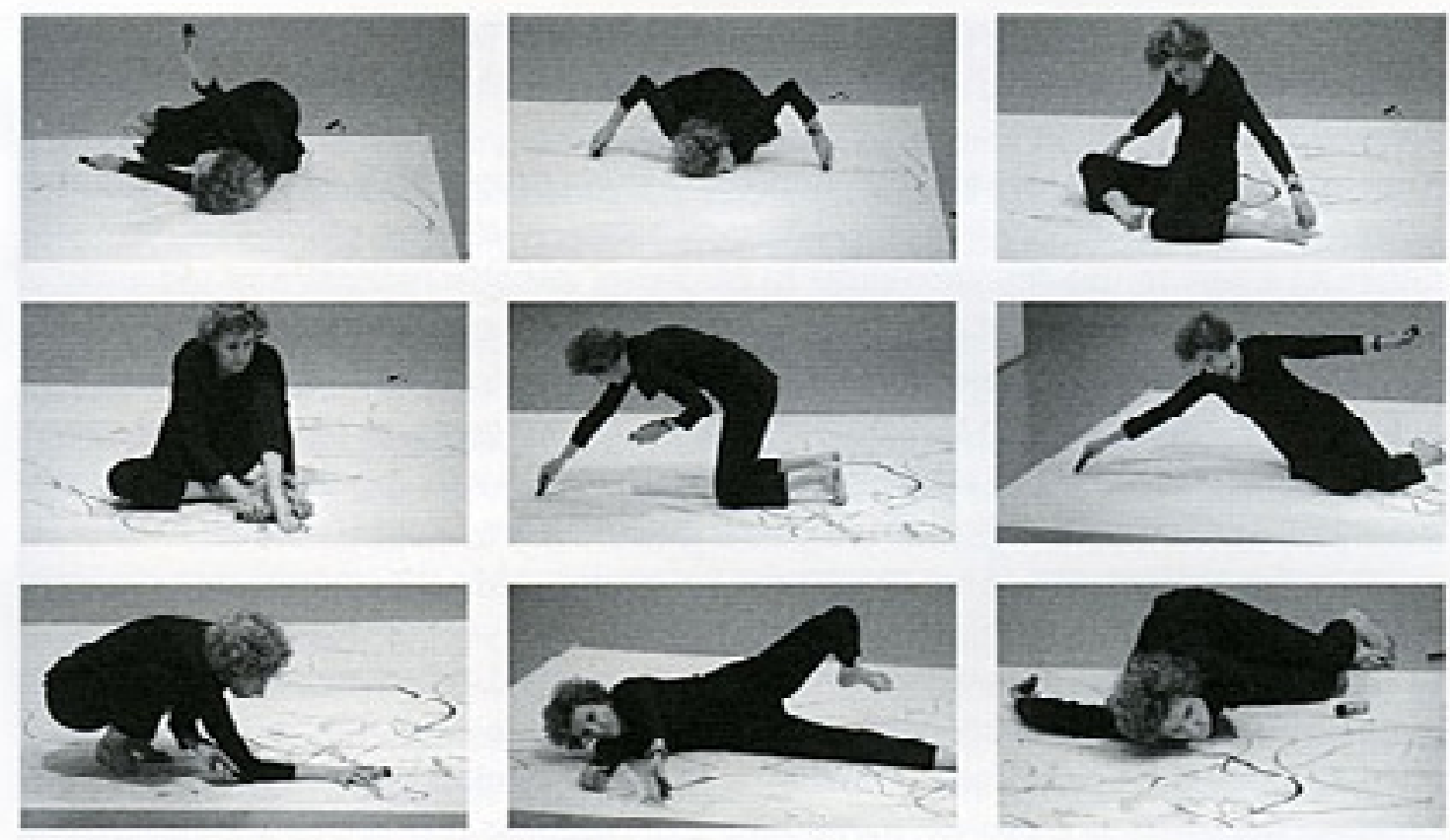

It's a Draw. Performance apresentada por Trisha Brown, na qual a artista utiliza movimentos corporais para criar desenhos abstratos ${ }^{17}$

\footnotetext{
${ }^{16}$ Issues of the body and its powerful social meanings were approached head on. The body itself became the subject of the dance, rather than serving as an instrument for expressive metaphors. An unabashed examination of the body and its functions and powers threaded through the early postmodern dances. [...] Choreographers deliberately used untrained performers in their search for the "natural" body. Ex: Brown, Forti and Dick Levine's "violent contact" improvisations. (1961) (Tradução nossa)

${ }^{17}$ Fonte: http://www.trishabrowncompany.org/?page=view\&nr=108. Acesso em: 17 nov. 2017.
} 
O objetivo de realizar desenhos ao vivo e em movimento, que aparecem em It's a Drawn, pode ser comparado à ideia de action painting, conceito desenvolvido em 1952 por Harold Rosenberg. Sobre essa técnica artística pode-se afirmar:

Em um certo momento a tela começou a aparecer, para um pintor americano atrás do outro, como uma arena para se atuar- Ao invés de ser um espaço onde se reproduz, redesenha, analisa ou 'expressa" um objeto, atual ou imaginado. $\mathrm{O}$ que aconteceria na tela não era uma pintura, mas um evento. $O$ pintor não mais aborda o seu cavalete com uma imagem na mente; ele vai até o cavalete com um material nas suas mãos para fazer algo com aquele outro pedaço de material na sua frente. A imagem seria o resultado desse encontro. (Rosenberg, 1952, p. 22$)^{18}$

A partir dessa análise feita por Rosenberg, percebe-se uma tendência da action painting em transformar uma pintura em uma apresentação. A tela se transforma no palco dessa performance e a ação de criar imagens se transforma na temática principal desse espetáculo. O foco dessa manifestação de arte acaba sendo o processo de produção da imagem, e não o resultado final da experimentação.

Quando Brown apresenta o seu trabalho It's a Drawn, a artista põe em evidência os gestuais adotados para criar uma forma abstrata no local onde estão sendo desenvolvidos os seus desenhos. Por ser uma artista da dança, Brown utiliza a sua capacidade de experimentação de diferentes movimentos corporais para desenvolver novas formas abstratas. A artista consegue brilhantemente unir técnicas da dança e do desenho no momento que está apresentando essa produção.

Um espetáculo que se aproxima aos ideais propostos por Brown em It's a Drawn é a obra Up to and Including Her Limits, de Carolee Schneeemann. Nesse trabalho, a artista desenha, alternadamente, com roupa ou nua, nas paredes e no teto de um recinto anexo ao local de apresentação. A movimentação é realizada com a artista presa a um equipamento de escalada preso ao teto. Scheneemann desenha em certos momentos de olhos fechados, às vezes com apenas a visão de um olho e outras vezes com os olhos abertos. Os movimentos também alternavam velocidades (Eyland, 2016).

Alguns pontos dessa obra se relacionam com a série produzida por Brown, como o uso do movimento do corpo para a realização de desenhos abstratos, o fato de as duas artistas desenvolverem as suas criações com seus corpos se locomovendo, além de os dois trabalhos terem sido apresentados ao vivo, com o objetivo de apresentar a ação de desenhar, sem se preocupar com o resultado final das experimentações abstratas.

\footnotetext{
${ }^{18}$ At a certain moment, the canvas began to appear to one American painter after another as an arena in which to act- rather than as a space in which to reproduce, re-design, analyze or "express" an object, actual or imagined. What was to go on the canvas was not a picture but an event. The painter no longer approached his easel with an image in his mind; he went up to it with material in his hand to do something to that other piece of material in front of him. The image would be the result of this encounter. (Tradução nossa)
} 


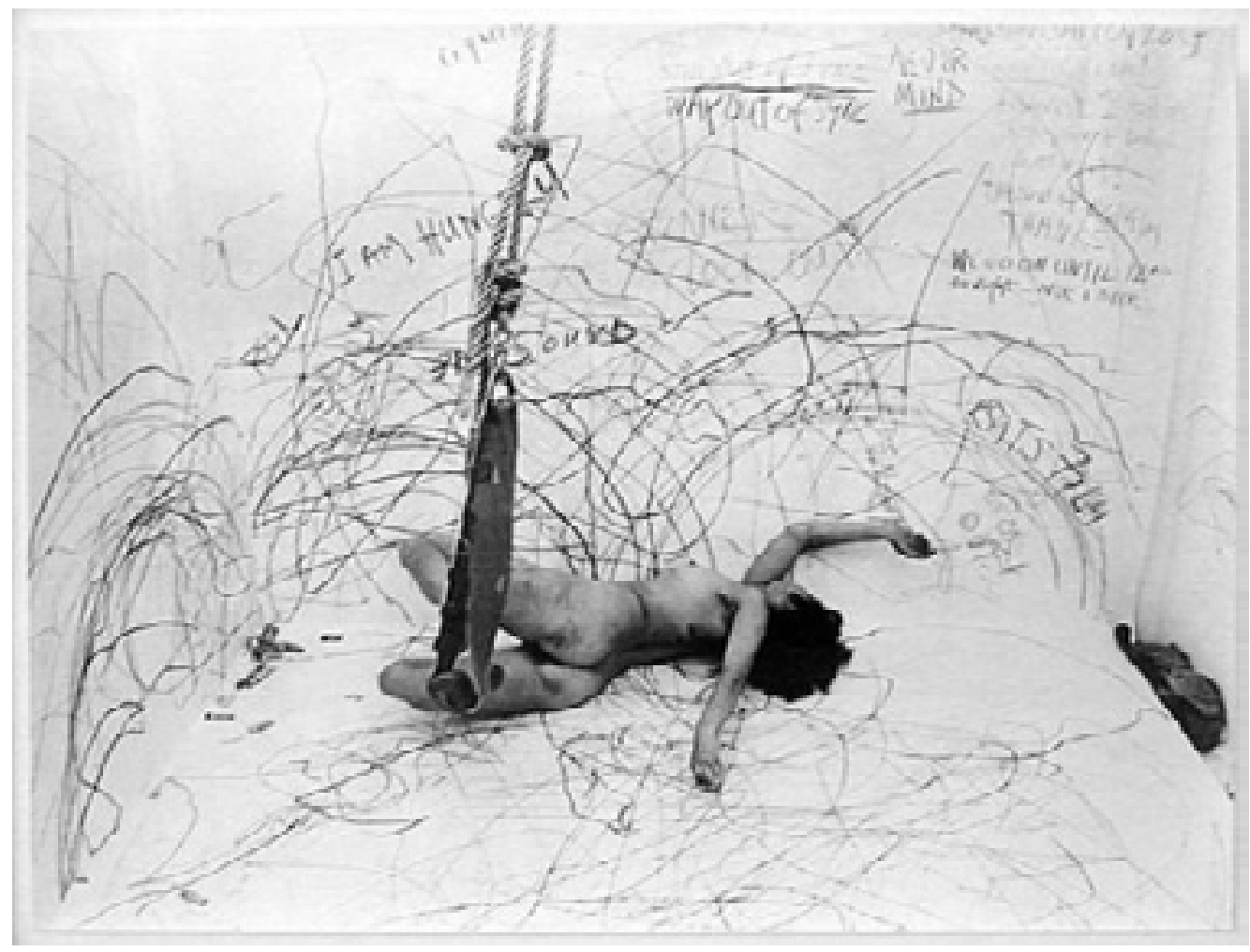

Up to and Including Her Limits. Performance apresentada por Carolee Schneemann ${ }^{19}$

Pode-se concluir que a contemporaneidade abriu novos caminhos para a arte, principalmente para a dança contemporânea. Os artistas tornaram-se mais livres para experimentar novos e diferentes elementos e para executarem os seus ideais de forma mais abstrata e ousada, o que resultou na busca por novos materiais e linguagens para a construção de seus espetáculos de dança.

A dança contemporânea trouxe, então, novas perspectivas para essa arte e uma dessas novas abordagens foi a união com outras formas artísticas. Trisha Brown foi uma representante importante no movimento pós-moderno e ajudou na construção de novas propostas para o campo artístico a partir de suas experimentações. A coreógrafa, que procurou nas artes visuais instrumentos que a ajudassem na construção de seu estilo próprio, conseguiu misturar diversas formas artísticas em seus trabalhados, desconstruindo os limites da dança.

Trisha Brown teve potencial para unir princípios de diferentes manifestações artísticas sem perder a sua essência criadora que representava a sua vontade de desconstruir o que the era imposto como dança e construir seu próprio estilo em suas criações. Mesmo utilizando diversos recursos em suas produções, a sua visão sobre dança como desafiadora do corpo, do espaço e da gravidade foi o impulso principal para sua construção coreográfica.

Brown utilizou elementos das artes visuais para ampliar a abstração e estranhamento de suas peças, enriquecendo os padrões comuns de um espetáculo de dança. Em um primeiro momento, os recursos das artes visuais se tornam instrumentos para engrandecer suas peças. O vídeo, por exemplo, se aglomerou com a dança da artista para transformar as ideias propostas por seus gestuais. Essa ferramenta serviu para

${ }^{19}$ Fonte: https://www.moma.org/learn/moma_learning/carolee-schneemann-up-to-and-including-her-limits-1973-76. Acesso em: 17 nov. 2017. 
exploração da dança de Brown em outras arquiteturas e para auxiliar na memorização coreográfica. Nesse ponto, por mais que a coreógrafa estivesse usando um recurso das artes visuais, o seu foco estava direcionado para a construção de suas danças.

Em outra fase de sua obra, a bailarina norte-americana começa a desenvolver os seus próprios desenhos. Esses trabalhos são idealizados para auxiliar no estudo do corpo que dança porque esse instrumento gráfico se transforma em uma ferramenta para explorar a matéria orgânica. Brown conseguiu separar o corpo em menores partes por causa dos desenhos. Adicionalmente, o desenho lhe deu mais liberdade que o corpo orgânico para os estudos de posições e movimentos. Por resultado, esse elemento ajudou na memorização e construção gestual das peças da coreógrafa porque a dança era pesquisada através dessa ferramenta. O recurso da arte visual se torna, então, um objeto para o estudo da dança.

Em outro período, a coreógrafa produziu live performances que constituíram a série It's a Drawn, que mesmo que não faça parte de apresentações de dança, se relaciona com os temas do corpo e da dança. Nessas criações, o corpo da artista se transformava na ferramenta da pintura abstrata. Nesse ponto, é difícil decidir se Brown estava pintado com seu corpo ou dançando com tintas e giz. Essas obras representam um maior mergulho da bailarina nas artes visuais. Não que sua dança esteja ausente, mas o foco na produção de arte visual se torna mais aparente nesses experimentos.

Para Banana (2012) nas danças de Trisha Brown o que conta são as distintas relações que emergem entre corpos, ações e materiais. Ao unir as artes visuais com a dança, a coreógrafa desenvolveu uniões que agregaram novas ideias para os seus trabalhos. Mesmo trabalhando com recursos de outras linguagens, o foco da artista era a dança e o estudo corporal. Mesmo em It's a Drawn, uma performance de arte visual, o corpo e a sua dança estavam presentes. Esses recursos também foram importantes para o entendimento do funcionamento corporal em movimento, ampliando as pesquisas de Brown sobre os limites da matéria orgânica.

Dessa forma, os elementos independentes da dança e da arte visual são trabaIhados em conjunto nos trabalhos de Trisha Brown para a elaboração de novas percepções, fazendo com que o público e a crítica em contato com as suas peças pudessem refletir sobre o que estava acontecendo e o que estava sendo mostrado em cena.

\section{Referências}

BANES, Sally. Terpsichore in Sneakers: Post-Modern Dance. Middletown: Wesleyan University Press, 1979. Versão kindle.

Democracy's body: Judson Dance Theatre. Londres: Duke University Press, 1993. Versão kobo.

BANANA, Adriana. Trishapensamento: espaço como previsão meteorológica. Belo Horizonte: Clube Ur=HOr, 2012.

BATTCOCK, Gregory. Minimal Art: A Critical Anthology. Nova lorque: E.P Dutton, 1968. 
BAUDRILLLARD, Jean. Tela total: mito-ironias da era virtual e da imagem. 3ed. Porto Alegre: Sulina, 2002.

BUARQUE DE HOLANDA, Heloisa. Pós-modernismo e política. Rio de Janeiro: Rocco, 1991.

BURT, Ramsay. Judson Dance Theater: Performative traces. Nova lorque: Routledge, 2006. Versão kobo.

CLIMENHAGA, Royd. Pina Bausch. Abingdon: Routledge, 2009.

CUNNINGHAM, Merce. O dançarino e a dança: conversas com Jacqueline Lesschaeve. Rio de Janeiro: Cobogó, 2014.

DAl, Lu Shirley. Dancing and Drawing in Trisha Brown's Work: A Conversation Between Choreography and Visual Art. 2016. Senior Thesis in Dance and Art History. Columbia University. $58 \mathrm{p}$.

EYLAND, Cliff. Carolee Schneemann. Disponível em: <https://www.umanitoba.ca/ schools/art/content/galleryoneoneone/schneemann01.html>. Acesso em: 03 jan. 2017.

ELEEY, Peter. Trisha Brown: so that the audience does not know whether I have stopped dancing. Minneapolis: Walked Art Center, 2008.

FERREIRA, Glória; COTRIM, Cecilia. Escritos de artistas: anos 60/70. Rio de Janeiro: Jorge Zahar, 2006.

LEE, Lydia. Laurie Anderson, Trisha Brown, Gordon Matta-Clark: Pioneers of the Downtown Scene, New York 1970s. Nova lorque: Prestel, 2011.

GRAHAM. Amanda Jane. Space Travel: Trisha Brown's Locus. Art Journal. Nova lorque, 2016. Disponível em: <http://artjournal.collegeart.org/?p=7351>. Acesso em: 8 jan. 2016.

LEPECKI, André. Dance. Londres: MIT Press, 2012.

MACHADO, Arlindo. Arte e mídia. Rio de Janeiro: Jorge Zahar, 2010.

ROSENBERG, Harold. The American action painters. ART news. Nova lorque, 1952.

SCHIPHORST, Tecla. A case Study of Merce Cunningham's use of the Lifeforms computer choreographic system in the making of Trackers.1993. Thesis of Master Degree of Arts. Simon Fraser University. 99 p. 
SOMMERS, Sally. Equipment Dances: Trisha Brown. The Drama Review: TDR, vol. 16, n. 3, The "Puppet" Issue, p. 135-141,1972.

SPIVEY, Virginia B. The Minimal Presence of Simone Forti. Woman's Art Journal, vol. 30, n. 1, p. 11-18, 2009.

Recebido em: 05/06/2017 Aprovado em: 17/11/2017 